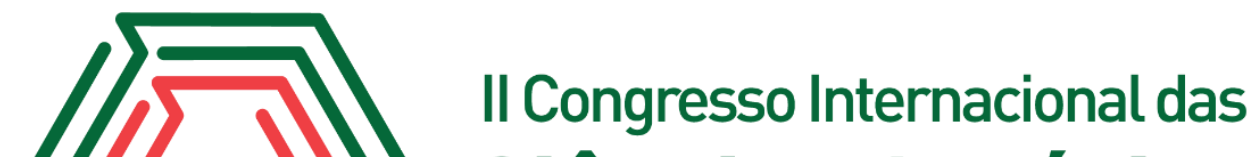 Ciências Agrárias COINTER - PDVAgro 2017
}

\section{DIAGNÓSTICO QUALITATIVO ACERCA DA ABORIZAÇÃO DE UMA PRAÇA NA CIDADE DE NATAL/RN}

\author{
Apresentação: Pôster \\ Carmem Sara Pinheiro de Oliveira ${ }^{1}$; Cynthia Firmino Aires ${ }^{2}$; José Custódio da Silva ${ }^{3}$; Heitor \\ Barbosa de Morais Bittencourt Dutra ${ }^{4}$; Fabíola Gomes de Carvalho ${ }^{5}$
}

\section{Introdução}

Desde os tempos mais antigos, a praça atua como espaço público marcado pela convivência humana, servindo como importante condutor históricocultural urbano que, especialmente no Brasil, manifesta-se por meio do surgimento e desenvolvimento de inúmeros cidades.

As praças desempenham diversas funções ambientais aos mais variados centros urbanos, podendo ser citado: melhoramento da qualidade do ar (fixação do dióxido de carbono $\left(\mathrm{CO}_{2}\right)$ e liberação de oxigênio $\left(\mathrm{O}_{2}\right)$, por meio do processo de fotossíntese), barreiras (servindo de obstáculos para a propagação do som e de resíduos sólidos presentes no ar), manutenção climática (reduzindo a temperatura e aumentando a umidade do ar), otimização do solo (facilitando o escoamento e absorção de águas pluviais).

Portanto, o planejamento correto e eficiente de praças públicas, é fundamental para um bom desenvolvimento urbano, pois caso isso não ocorra, o crescimento desenfreado das cidades pode se dá de maneira negativa, afetando a qualidade de vida da população.

Devido a esses fatores, o estudo teve por objetivo a obtenção de dados sobre a atual situação da Praça Miriam Vasconcelos, localizada em Natal - RN, para emitir um diagnóstico qualitativo acerca de sua arborização.

\section{Fundamentação Teórica}

\footnotetext{
${ }^{1}$ Mestra, Universidade Federal de Santa Catarina, carmem.sara@posgrad.ufsc.br

${ }^{2}$ Pós-graduanda em Uso Sustentável de Recursos Naturais, Instituto Federal do Rio Grande do Norte, cynthia_aires@hotmail.com

${ }^{3}$ Pós-graduando em Gestão Ambiental, Instituto Federal do Rio Grande do Norte, custodio.biologia@yahoo.com.br

${ }^{4}$ Pós-graduando em Gestão Ambiental, Instituto Federal do Rio Grande do Norte, heitor.br@gmail.com

${ }^{5}$ Doutora, Instituto Federal do Rio Grande do Norte, fabiola.carvalho@ifrn.edu.br
} 
O uso do verde urbano constitui-se em um dos espelhos do modo de viver dos povos que o criaram nas diferentes épocas e culturas. A priori, tinha função de agradar visualmente e olfativamente. Já no século XIX, estas áreas verdes assumem uma função utilitária, principalmente nas zonas urbanas densamente povoadas (LOBODA, 2005).

A história de praças e largos no Brasil, vem sendo contada já de longa data, desde os primórdios da colonização. Sobre estes espaços constituíam pontos de atenção e focalização urbanística, visto que em seu entorno haviam construções de maior apuro. (REIS FILHO, 1968).

Para Coletto et al. (2008), o planejamento da arborização urbana é imprescindível para o desenvolvimento das cidades e demanda conhecimento da condição existente, por meio de inventário quali-quantitativo, bem como o conhecimento dos atributos dos vegetais utilizados. Sendo assim, faz-se necessário uma análise da vegetação das praças, para que seja possível constituir a implementação de espécies adequadas nesses espaços.

Segundo Melo e Romanini (2008), nas cidades em que ocorre o planejamento das arborizações, a preocupação é transformar o ambiente urbano de modo que a diversidade, quanto às espécies empregadas, deixe o meio mais envolvente com a paisagem circundante. Desse modo, a importância do estudo é viabilizada por meio da necessidade no aumento da consciência sobre questões ambientais que tem buscado soluções para mitigar os impactos na natureza, promovendo uma melhoria na qualidade de vida.

\section{Metodologia}

O estudo foi realizado na Praça Miriam Vasconcelos, popularmente conhecida como "Praça do SESC", que fica localizada no conjunto Potilândia, bairro de Lagoa Nova, município Natal do Estado do Rio Grande do Norte. Os instrumentos e demais materiais utilizados e as respectivas finalidades são os seguintes: caderno de planilhas para as anotações; trena de 50m e fita métrica de $1 \mathrm{~m}$ para altura da primeira bifurcação, largura da calçada e do diâmetro da copa. Para a composição do trabalho, foi realizado um inventário com todos os indivíduos (árvores) contidos na praça.

Foram medidos e anotados todos os dados considerados importantes para a avaliação da arborização, no qual foi norteado segundo a planilha desenvolvida por Silva Filho (2002), onde é apresentada a seguinte organização: Localização e identificação, Biologia (Estado geral, Equilíbrio geral, Aspectos fitossanitários, Intensidade, Local do ataque, Injúrias e Ecologia), Entorno e 
interferências (Localização geral, Localização relativa, Pavimento da calçada, Afloramento de raiz, Participação, Tipo de fiação, Recuo, Situação adequada, Colo pavimentado e Fiação, Posteamento, iluminação, sinalização, muro/construção).

A pesquisa ocorreu durante o mês de setembro de 2017 e os dados foram tabulados no Excel para posterior consulta.

\section{Resultados e Discussões}

A Praça do SESC, foi escolhida para a realização do estudo devido a sua localização estratégica, demanda por utilização de usuários de áreas próximas e sua importância histórica para os usuários residentes no conjunto Potilândia em Natal/RN.

No levantamento foram identificadas 14 indivíduos arbóreos, sendo uma Palmeira, como segue na Figura 1 e Tabela 1 abaixo:

Figura 1: Croqui esquemático da praça do SESC em Natal/RN, onde A são as árvores e P são os postes. Fonte: Própria

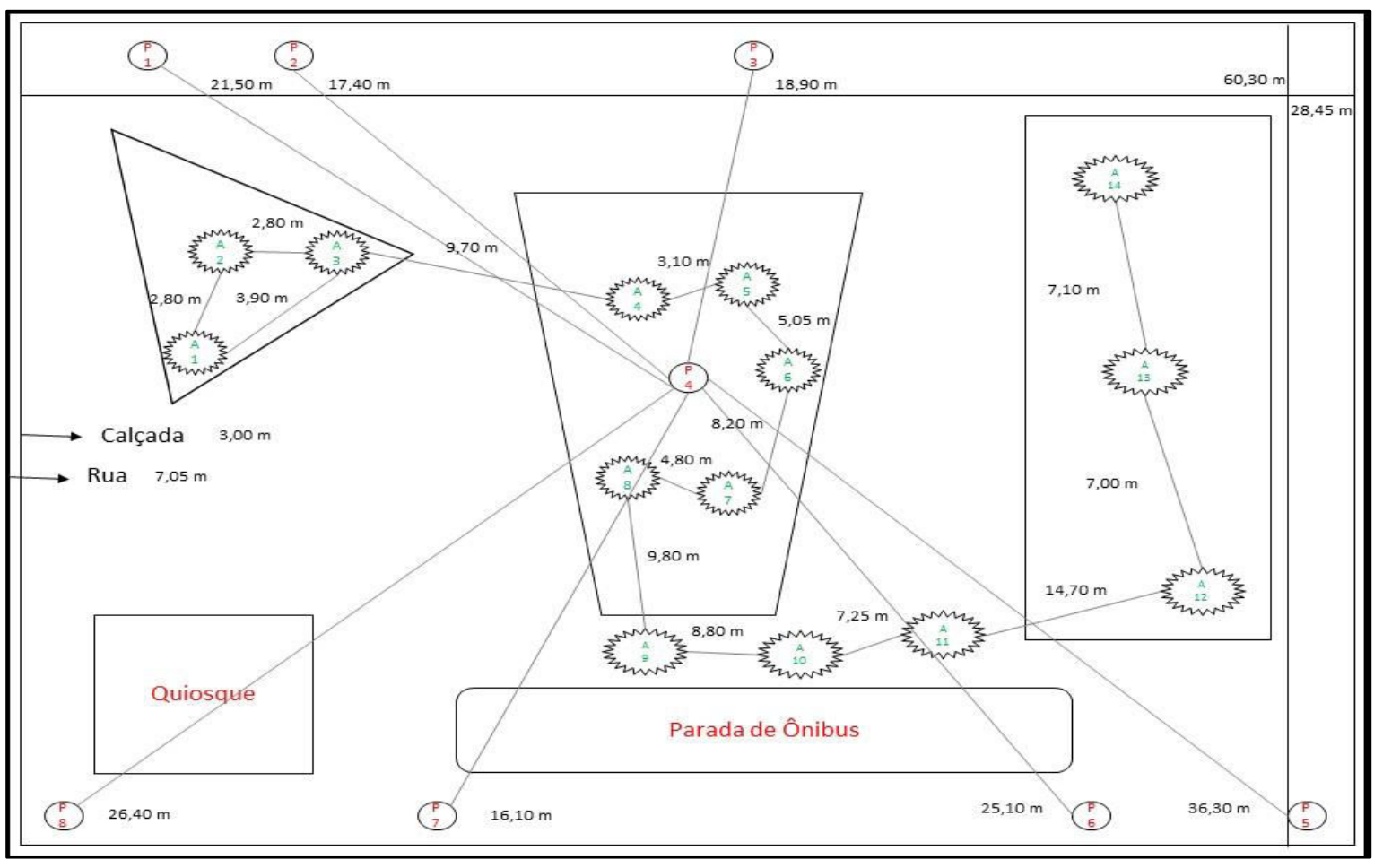

Na figura acima é possível visualizar que as distancias entre as árvores e a calçada se dá de maneira adequada.

Tabela 1: Relação do nome popular, científico, origem e número de indivíduos encontrados na praça do SESC em Natal/RN. Fonte: Própria 


\begin{tabular}{|c|c|c|c|}
\hline Nome popular & Nome científico & Origem & $\mathbf{N}^{\mathbf{0}}$ de indivíduos \\
\hline Coqueiro & Cocos nucifera & Exótica & 1 \\
\hline Mangueira & Mangifera indica & Exótica & 4 \\
\hline Palmeira & Arecaceae & Exótica & 1 \\
\hline Ipê-roxo & Handroanthus impetiginosus & Nativa & 2 \\
\hline Castanhola & Terminalia catappa & Exótica & 2 \\
\hline Azeitona preta & Syzygium jambolanum & Exótica & 4 \\
\hline
\end{tabular}

Na tabela acima é possível identificar que cerca de $93 \%$ dos espécimes plantados no local são exóticos. De acordo com Rezende e Santos (2010), um grande número de indivíduos exóticos pode demonstrar uma ausência de preocupação com a conservação da flora nativa, o que deve ser repensando de modo a efetivar um planejamento da (re) arborização que deverá contribuir para a preservação das espécies nativas.

No que diz respeito a Biologia, o Estado Geral encontra-se bom, não apresentando ataques ou injúrias; o Equilíbrio geral foi visto como equilibrado, com eixo simétrico; o Aspecto fitossanitário verificado a olho nu apresentou apenas formigas; a Intensidade na medida que verificado foi classificado como leve, onde não causou danos; o Local do ataque foram: caule, raiz, frutos, flores, ramos e/ou folhas; as Injúrias observadas foram apenas vandalismo; a Ecologia: presença de insetos e liquens.

Com relação ao Entorno e interferências, a Localização geral no canteiro central e na calçada; a Localização relativa centrada na calçada; o Pavimento da calçada de cimento; o Afloramento de raiz no canteiro; a Participação dois ou mais indivíduos da mesma espécie próximos; o Tipo de fiação encontrado foi de energia e de telefonia; o Recuo existe entre as árvores e as construções; a Situação adequado não possui conflitos com equipamentos ou construções; o Colo pavimentado possui pouco solo exposto; a Fiação, posteamento, iluminação, sinalização são de caráter atual, ou seja, estão em contato com os espécimes vegetais, já muro ou construção encontram-se ausentes.

As interferências de fiação e posteamento, muitas vezes, são derivadas de uma poda má realizada, o que pode acabar destruindo a estrutura das árvores. Uma possível solução para tais problemas, além da poda adequada, seria o isolamento ou proteção da fiação elétrica, modificações na disposição dos fios e dos postes, modificações nos sistemas de iluminação pública, troca da fiação aérea pela subterrânea (CEREZO e MARTINS, 1994). É interessante ressaltar que o vandalismo existe na praça, entretanto o mesmo se faz evidente em forma de pichações apenas na estátua que fica ao centro da mesma. Resíduos sólidos também foram encontrados em pequena 
quantidade. Sendo assim, observa-se a necessidade de acompanhamento técnico para o planejamento e implantação correta da manutenção nestas áreas, a fim de garantir um melhor aproveitamento de todos os sujeitos envolvidos no meio.

\section{Conclusões}

Pode-se concluir que o estudo demonstrou uma certa falta de planejamento arbóreo, principalmente no que diz respeito à diversidade, manejo, manutenção e escolha das espécies devido ao grande número de espécies exóticas. Entretanto, não foi observado pragas, patógenos ou vandalismo. Sugere-se, portanto, que se proceda um acompanhamento técnico periódico para a manutenção dessas praças, a fim de garantir ao espaço verde um maior tempo de ação.

\section{Referências}

CEREZO, F. L. B.; MARTINS, C. S. Poda e arborização urbana em Belo Horizonte. In: CONGRESSO BRASILEIRO DE ARBORIZAÇÃO URBANA, 2, São Luiz, 1994. ENCONTRO NACIONAL SOBRE ARBORIZAÇÃO URBANA, 5, São Luiz, 1994. Anais... São Luiz: Sociedade Brasileira de Arborização Urbana, 1994. p. 377-387.

COLETTO, E. P.; MULLER, N. G.; WOLSKI, S. S. Diagnóstico da arborização das vias públicas do município de Sete de Setembro - RS. REVSBAU, Piracicaba, v.3, n.2, p.110-122, 2008.

LOBODA, C. R.; DE ANGELIS, B. L. D. Áreas verdes públicas urbanas: conceitos, usos e funções. Ambiência, Guarapuava, v.1, n.1, p.125 - 139, 2005.

MELO, E. F. R. Q; ROMANINI, A. Praça Ernesto Tochetto: importância da sua preservação histórica e aspectos de sua arborização. Revista da Sociedade Brasileira de arborização Urbana. Piracicaba, v. 3, n. 1, p. 54-72, 2008.

REIS FILHO, N. G. Contribuição ao estudo da evolução urbana no Brasil (1500/1720). São Paulo: EDUSP, 1968.

REZENDE, T.M.; SANTOS D.G. AVALIAÇÃO QUALI-QUANTITATIVA DA ARBORIZAÇÃO DAS PRAÇAS DO BAIRRO JARAGUÁ, UBERLÂNDIA - MG. REVSBAU, Piracicaba - SP, v.5, n.2, p.139-157, 2010.

SILVA FILHO, D. F. Cadastramento informatizado, sistematização e análise da arborização das vias públicas da área urbana do município de Jaboticabal, SP. Jaboticabal, 2002. 81 p. Dissertação (Mestrado) - Faculdade de Ciências Agrárias e Veterinárias, Universidade Estadual Paulista "Júlio de Mesquita Filho". 
. 